\title{
Deleção do cromossomo 9 na região q22q32 em bebê com cariótipo 46XY: relato de um caso
}

\section{Deletion of chromosome 9 in the region q22q32 in a male baby with karyotype 46XY: report of a case}

Seme Youssef Reda'; Jean Ricardo Nicareta ${ }^{2}$

\section{unitermos $\operatorname{Del}(9)(q 22 q 32)$ \\ Deleção do cromossomo 9 Cariótipo 46XY del(9)}

\section{resumo}

Este trabalho teve como objetivo o estudo laboratorial e por imagem das malformações de um bebê do sexo masculino que apresentou, por ocasião do parto, prematuridade, cardiopatia congênita, insuficiência respiratória e malformação congênita. O estudo ecográfico gestacional mostrou o osso nasal hipoplásico e a coluna vertebral com pequeno desvio na transição entre a coluna cervical e a torácica. No coração foi constatada a presença de Golf-Ball em ventrículo esquerdo e no trato genitourinário, pielectasia renal bilateral. Os estudos citogenéticos diagnosticaram deleção intersticial do cromossomo 9 do segmento q22q32 no braço longo, onde se estabeleceu o cariótipo 46,XY,del(9)(q22q32).

\section{abstract}

This study aimed at the laboratory and imaging investigation of malformations in a male baby that presented prematurity, congenital cardiopathy, respiratory failure and congenital malformation at the time of delivery. The gestational ultrasonography showed a hypoplastic nasal bone and a minor spinal deviation at the transition between the cervical and thoracic spine. There was Golf-Ball in the left ventricle and, in the genitourinary tract, bilateral renal pyeloectasis was observed. Cytogenetic studies revealed interstitial deletion of chromosome 9 from the segment q22q32 in the long arm, where the karyotype 46, XY, del (9) (q22q32) was identified. 


\section{Introdução}

As deleções envolvendo o braço longo do cromossomo 9 são raras e, entre alguns casos já publicados, citam-se a deleção específica em região eucromática del(9)(q32q34) e a deleção intersticial do cromossomo 9 na região $\mathrm{q} 22 \mathrm{q} 32^{(4,6)}$.

Achados importantes nesse tipo de anomalia gênica são as malformações intra-uterinas, como oligoidrâmnio, orelhas rudimentares, pulmões e ureteres pouco desenvolvidos, micrognatia com palato estreito, alto e arqueado, linhas bilaterais do pescoço mais baixas na parte posterior e anomalias cardíacas complexas $(2,3,5)$.

Em nascidos vivos que sobrevivem por algum tempo, observam-se severo retardo mental e dismorfismo ${ }^{(4)}$.

Neste trabalho foi relatado um caso de severo dismorfismo intra-uterino em bebê do sexo masculino com alteração do cromossomo 9, na região q22q32, em hospital na cidade de Guarapuava (PR).

\section{Método}

Para o acompanhamento intra-uterino do bebê foi utilizado estudo ecográfico de três dimensões, e para os exames laboratoriais foram feitas as seguintes determinações:

- hepatite B: antígeno de superfície do vírus da hepatite B (HBsAg) por quimiluminescência em soro;

- vírus da imunodeficiência humana 1 e 2 (HIV-1 + HIV-2): pesquisa de anticorpos por enzima imunoensaio (EIA) fase sólida em soro;

- toxoplasmose (Toxo): pesquisa de imunoglobulinas das classes G e M (lgG e lgM) por quimiluminescência em soro;

- pesquisa laboratorial de doenças venéreas (VDRL): microfloculação em soro;

- glicemia (Glico): enzimático-automatizado em soro;

- hemograma (Hemo): automatizado-coulter;

- urina I e II (Uri): clinitek-sedimentoscopia

Para a pesquisa do cariótipo do bebê foi utilizada cultura de células de longa duração "em frasco", em vilosidades coriônicas, com 20 metáfases contadas e oito analisadas, utilizando-se Giemsa-tripsina-Giemsa (GTG) como técnica de bandeamento em duas culturas.

Para a análise dos cariótipos dos pais foi utilizada a cultura padrão temporária de linfócitos, em sangue periférico, com 20 metáfases contadas e cinco metáfases analisadas, utilizando-se GTG como técnica de bandeamento em uma cultura.

\section{Relato do caso}

Bebê do sexo masculino, com $1.880 \mathrm{~g}$ de peso, nasceu com 33 semanas de gestação de parto cesárea devido a descolamento prematuro de placenta.

Apresentou, na ocasião do parto, prematuridade, cardiopatia congênita, insuficiência respiratória e malformação congênita, com teste de Apgar 4 no primeiro minuto e 7 no quinto minuto, entrando em óbito com um dia de vida.

A causa intrínseca das malformações foi diagnosticada como deleção do cromossomo 9 na região q22q32.

\section{Discussão}

As malformações encontradas no bebê tiveram como base um acidente genético envolvendo uma deleção em regiões do braço longo do cromossomo 9, especificamente na região q22q32, conforme diagnóstico citogenético realizado, corroborando os achados de Ying et al.(6) $\mathrm{e}$ Friedman $^{(1)}$

A Figura 1 mostra uma representação esquemática dos genes do homólogo do cromossomo 9 em um sistema de bandas e a região onde a alteração genética ocorreu.

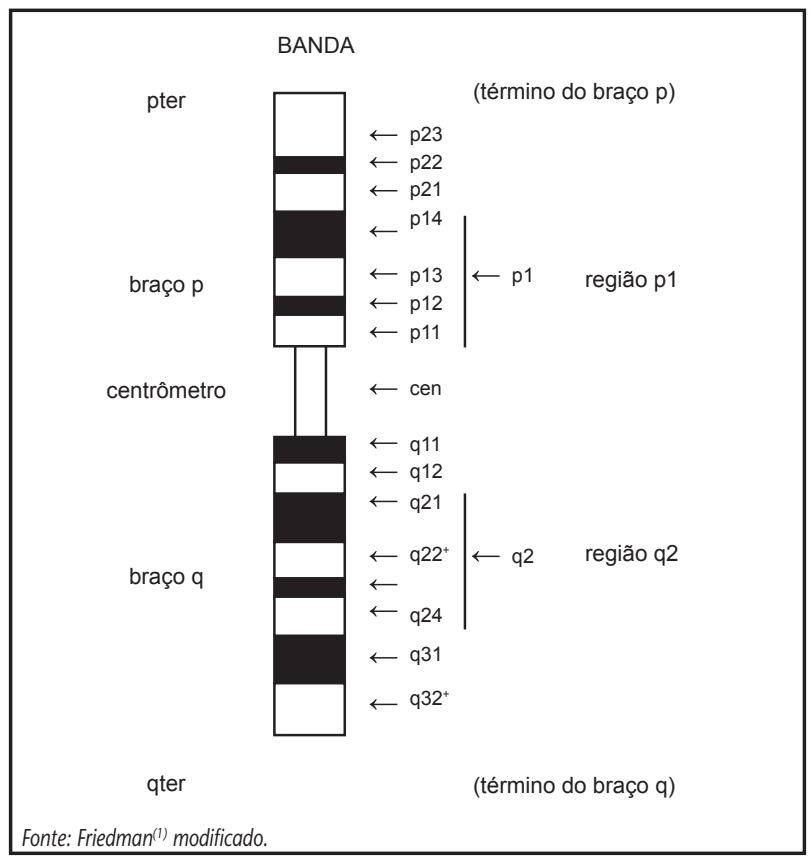

Figura 1 - Esquema mostrando as regiões específicas do cromossomo 9, onde ocorreu a alteração gênica 
Em contraste com as malformações congênitas encontradas no bebê, os exames laboratoriais não revelaram nenhuma patologia prévia na mãe, conforme mostra a Tabela.

\begin{tabular}{lc} 
Tabela & $\begin{array}{l}\text { Resultado dos exames laboratoriais } \\
\text { da mãe }\end{array}$ \\
\hline Exames & Resultado \\
\hline Hepatite B & NR \\
HIV-1 & NR \\
HIV-2 & NR \\
Toxo & NR \\
VDRL & NR \\
Glico (mg/dl) & 90 \\
Hemo & $\mathrm{N}$ \\
Urina I e II & $\mathrm{N}$ \\
NR = não-reagente; Toxo: toxoplasmose; VDRL: pesquisa laboratorial \\
de doenças venéreas; Glico: glicemia; Hemo: hemograma; N = valores \\
normais.
\end{tabular}

Contudo o estudo ecográfico da gestação revelou alteração na translucência nucal, em 7,1 mm, com 13 semanas, sendo que o saco gestacional ocupava toda a cavidade uterina, com implantação corial normal e ausência de áreas de descolamentos ou hematomas.

Com 16 semanas, o estudo ecográfico revelou alterações morfológicas no feto, na forma de micrognatia, corroborando os achados de Sharony et a ${ }^{(5)}$, edema nucal, pielectasia renal bilateral discreta, alteração cardíaca na forma de Golf-Ball em ventrículo esquerdo, o que está de acordo com o encontrado por Kleyman et al.(3), bem como desvio da coluna em região cervicotorácica (Figura 2).



Figura 2 - Estudo ecográfico gestacional
Com 21 semanas de gestação foi realizado estudo morfológico ecográfico gestacional pela técnica de morfologia fetal segmentar.

Foi possível observar o pólo cefálico com ecoestrutura e aspectos da fossa posterior, dos pedúnculos cerebrais, do tálamo e do septo pelúcido normais. O osso nasal mostrouse hipoplásico e, na visualização das órbitas e cristalinos, observou-se hipotelorismo. Na coluna vertebral ficaram constatadas as alterações observadas no estudo ecográfico anterior, em que se confirmou a presença de pequeno desvio na transição entre a coluna cervical e torácica, alteração confirmada por ocasião do parto. Também foi ratificada a presença de Golf-Ball em ventrículo esquerdo, em que o coração apresentou quatro câmaras de proporções normais e ritmo cardíaco sinusal, assim como a observação do trato genitourinário mostrou áreas renais de aspecto normal, bexiga presente e de conformação normal. Entretanto, confirmou-se pielectasia renal bilateral. O líquido amniótico apresentou-se no limite superior de normalidade.

No estudo do cariótipo com bandeamento de vilosidade coriônica do feto, os estudos citogenéticos realizados pelo método de culturas primárias de longa duração "em frasco" das vilosidades coriônicas revelaram anormalidade estrutural em um dos homólogos do cromossomo 9 (Figura 3). Logo, foi constatada uma deleção intersticial do segmento q22q32 no braço longo do cromossomo 9 em cada célula examinada em uma resolução de 400 bandas. $O$ estudo citogenético também estabeleceu o cariótipo 46,XY, del(9)(q22q32) como o do bebê em estudo.

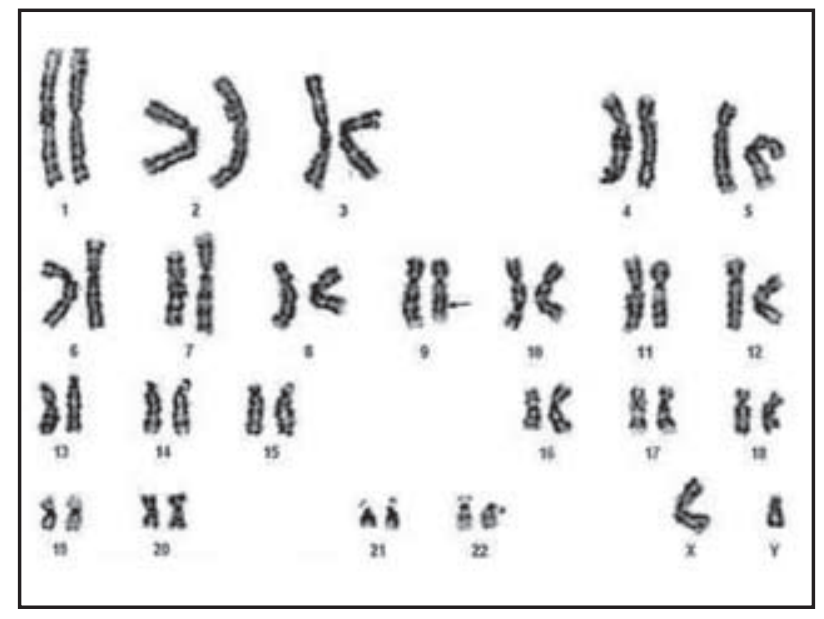

Figura 3 - Representação esquemática mostrando o segmento do braço longo do cromossomo 9

Os estudos citogenéticos dos cariótipos dos pais, realizados em linfócitos estimulados de sangue periférico, revelaram não haver anormalidade cromossômica, numérica ou estrutural, em uma resolução de 400 bandas. 


\section{Conclusão}

No estudo do cariótipo com bandeamento de vilosidade coriônica do bebê, os estudos citogenéticos revelaram anormalidade estrutural em um dos homólogos do cromossomo 9, constatando-se deleção intersticial do segmento q22q32 no braço longo. O estudo citogenético também estabeleceu o cariótipo 46,XY,del(9)(q22q32) do bebê.

As pesquisas ecográficas demonstraram diversas malformações intra-uterinas, manifestadas por ocasião do parto, como prematuridade, cardiopatia congênita e insuficiência respiratória.

As anomalias apresentadas, diagnosticadas e confirmadas pelos métodos aqui descritos, determinaram a incompatibilidade de sobrevivência do nascituro.

\section{Agradecimentos}

Agradecemos à prefeitura de Guarapuava e à enfermeira Sílvia Silveira por sua colaboração na realização desse artigo.

\section{Referências}

1. FRIEDMAN, J. M. Interpreting chromosomal abnormalities. Disponível em: <http://www.newdalesystems.com/ articles/Article006.pdf>. Acesso em: 1 dez. 2008.

2. KARGAS, S. A. et al. Newborn infant with del(9)(pterrarrq32:) and multiple congenital anomalies including arrhinencephaly, cardiac malformations and rudimentary ears. Am J Med Genet, v. 28, p.161-6, 1987.

3. KLEYMAN, S. M. et al. Paracentric inversion involving the long arm of chromosome 9 resulting in deletion of $a b /$ gene. Am J Med Genet, v. 68, p. 409-11, 1997.
4. KROES, H. Y. et al. Another patient with an interstitial deletion of chromosome 9: case report and a review of six cases with del(9)(q22q32). J Med Genet, v. 31, p.156-8, 1994.

5. SHARONY, R. et al. Prenatal diagnosis of pericentric inversion in homologues of chromosome 9: a decision dilemma. Am J Perinatol, v. 24, n. 2, p.137-40, 2007.

6. YING, K. L. et al. Case reports. J Med Genet, v. 19, p. 6876, 1982. 